\title{
Insulation effect evaluation model of green building materials under ecological environment
}

Ji Y.*

Zhejiang University of Technology Engineering Design Group Co., Ltd, Hangzhou 310014, China

Received: 06/07/2020, Accepted: 04/08/2020, Available online: 22/10/2020

*to whom all correspondence should be addressed: e-mail: zgdjiyiqun@163.com

https://doi.org/10.30955/gnj.003406

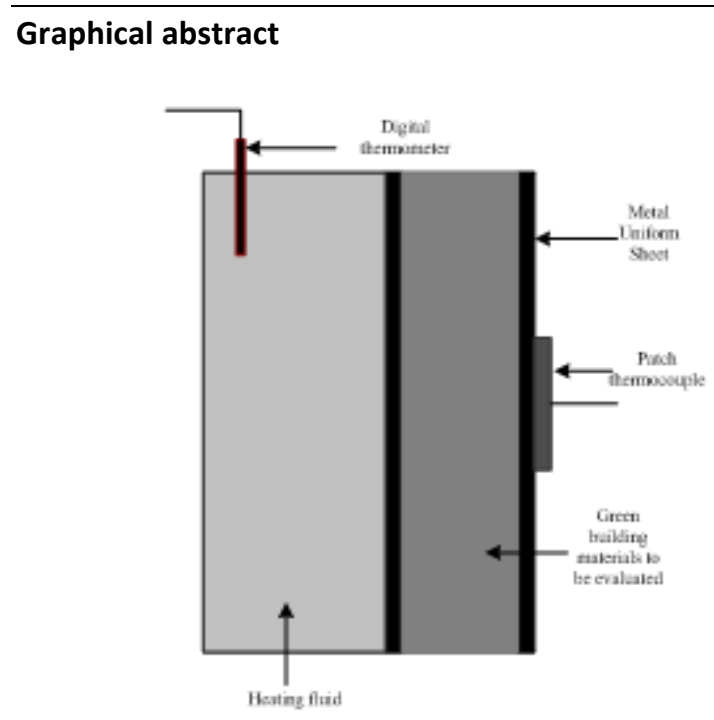

\section{Abstract}

Green building materials are an important material basis for promoting the development of green buildings, and also the foundation of building energy conservation. In view of this, an insulation effect evaluation model of green building materials is constructed. The outer wall temperature index, the equivalent thermal resistance index, the inner surface maximum temperature and the thermal inertia index are used to characterize the insulation effect of the green building materials. According to the insulation effect evaluation principle of green building materials, the outer surface and inner surface temperature deviation curves and its' fitting curves are made. The integral area between the fitting curve and the standard line is the temperature factor. The temperature factor can be used as an evaluation parameter for the insulation effect of green building materials in a fixed temperature range. It can characterize the average insulation effect of green building materials under a certain temperature range and comprehensive evaluation of different characterization indicators. The greater the temperature factor value is, the better the insulation effect is. The experimental results show that the model can accurately reflect the overall insulation effect of green building materials under the influence of various indicators in a certain temperature range, and the evaluation accuracy is high.

Keywords: Ecological environment, green building materials, insulation effect, evaluation model, characterization index, temperature factor.

\section{Introduction}

For a long time, most Chinese construction units have used traditional building materials such as cement, concrete, glass, and ceramics (Marangoni et al., 2017). Although such materials have good durability and high environmental adaptability, most of these materials are non-renewable resources from the perspective of sustainable development (Muto et al., 2018). Excessive use of this type of material not only has a serious impact on the ecological environment, but also may cause China's overall ecological environment to decline year by year (Povarov 2016). Facing the severe environment and resource situation, changing the development model of high pollution and high energy consumption has become a top priority for the global construction industry.

Since the 20th century, countries around the world have been working on green building materials and developing their own green buildings. The development of green buildings is an indispensable aspect of building a resourceconserving and environment-friendly society (Puza et al., 2018). To achieve good development of green buildings, it is particularly important to promote the application of green building materials. Green building materials are the collective name for all materials that do not have pollution. The definition of green building materials is as follows (Geisler et al., 2016): using clean production techniques, with or without the use of natural ecological resources and energy. The use of solid waste to produce non-toxic, nonpolluting, non-radioactive materials that can be recycled after the end of life, as well as building materials that are conducive to ecological environmental protection and human health. Analysis of its connotation shows that the core requirements of green building materials are "energy saving, waste utilization, health", i.e. ecological environment considerations (Cappello et al., 2017). The fundamental attribute of using green building materials to construct green buildings is to minimize the impact on the 
ecological environment, which is the essential difference between green building materials and traditional building materials. Green building materials mainly focus on four aspects: raw material application, product manufacturing, use and waste disposal. Under the premise of ensuring the rational use of materials, how to reduce the ecological environment load and achieve the common development of environmental protection and health has become the primary goal of the Chinese construction industry at this stage (Abdikadir et al., 2018; Achille et al., 2020; D'Agata et al., 2020; Mohammad et al., 2019).

Insulation has always been the focus and focus of researchers in building energy efficiency and indoor thermal environment and is also a difficult and hot topic in building energy conservation and indoor thermal environment research (Katsumata et al., 2017). It is well known that the direct illumination of the sun raises the internal surface temperature of the building structure, which on the one hand severely deteriorates the indoor thermal environment of the building structure and negatively affects the health of indoor occupants (Sumislawska et al., 2016). Reducing heat loss in buildings in cold areas and avoiding heat transfer in hot areas require that the building's perimeter structure have a certain thermal resistance. Otherwise, the structure of the building will be too cold in winter and overheated in summer. In order to avoid this phenomenon and increase the comfort of living, it will seriously waste energy resources such as electric energy and water energy (Sun et al., 2019). On the other hand, heat transfer from the building's perimeter structure has led to a dramatic increase in building energy consumption, which has become a weak link in energy conservation throughout the building envelope (Zoeller et al., 2017). The GB/T50378-2006 green building evaluation standard is the specific standard for the implementation of the first green building evaluation in China. The standard for heat insulation and energy saving of the building exterior structure is proposed in combination with the GB50189 public building energy-saving design standard. In Guangzhou, where the hot summer and warm winter regions are concerned, about $10 \%$ to $12 \%$ of the annual energy consumption of air conditioners is caused by heat transfer from the building envelope. As the heat transfer weak link of the envelope structure, the roof has a large proportion of heat transfer energy consumption in the envelope structure. The purpose of heat insulation of the outer protective structure is to control the temperature of the inner surface not to be too high, and appropriately increase the attenuation and delay time (Liu, Liu, and Wang, 2019). As a model of energy-saving, comfortable, healthy and environmentally-friendly buildings, green buildings naturally pay sufficient attention to the insulation of building materials used in their external protective structures. Based on this, this paper constructs the insulation effect evaluation model of green building materials under ecological environment to effectively evaluate the thermal insulation properties of green building materials under ecological environment (Ch. et al.,
2018; Ibrahim et al., 2020; Nwankwoala et al., 2019; Siti et al., 2019).

\section{Materials and methods}

\subsection{Insulation effect characterization of green building materials}

There are three main ways of heat transfer: introduction transfer, convection heat transfer and radiation heat transfer (Haţiegan et al., 2016). The insulation effect of green building materials is determined by the combined effects of these three heat transfer methods. Solar reflectance and hemispheric radiance are two important evaluation indicators of insulation effect of green building materials. These two properties respectively mean blocking the heat transfer from the solar radiation to the outer structure of the building structure and realizing the return of the heat absorbed by the enclosure. The insulation effect of green building materials applied in buildings can be characterized by the following indicators: external surface temperature index, equivalent thermal resistance index, maximum internal surface temperature and thermal inertia index.

\subsubsection{External surface temperature index of green building materials}

Both solar reflectance and hemispherical emissivity are important factors in the surface temperature of green building materials (Naeini et al., 2019). When the surface of green building materials is exposed to sunlight, the external surface temperature at steady state is calculated according to Formula (1). If it is horizontal roof, it can be simplified to Formula (2):

(The amount of sunlight absorbed by the surface of the green building materials, the amount of radiant heat exchange of the green building materials to the sky, the convective heat transfer of the green building materials and the air, and the heat transferred from the green building materials to the indoor side are in the steady state equilibrium.)

$$
\begin{aligned}
\alpha I= & \varepsilon \sigma\left[\left(x_{\text {sky }}+x_{g} \varepsilon_{g}\right) T_{s}^{4}-x_{\text {sky }} T_{\text {sky }}^{4}-x_{g} \varepsilon_{g} T_{g}^{4}\right] \\
& +h_{c}\left(T_{s}-T_{a}\right)+\frac{T_{s}-T_{r}}{R_{0}+R_{i}} \\
\alpha I= & \varepsilon \sigma\left(T_{s}^{4}-T_{\text {Sky }}^{4}\right)+h_{c}\left(T_{s}-T_{a}\right)+\frac{T_{s}-T_{r}}{R_{0}+R_{i}}
\end{aligned}
$$

where, $\alpha$ is the solar absorption rate of green building materials, $\alpha=1-\rho_{s}$, of which $\rho_{s}$. is the surface reflectance of green building materials; $I$ is the solar radiation intensity, the unit is $\mathrm{W} / \mathrm{m}^{2}$ (according to the meteorological data); $\varepsilon$ is the hemispheric radiance; $\sigma$ is the Boltzmann constant, taking $5.66961 \times 10^{-8} \mathrm{~W} /\left(\mathrm{m}^{2} \bullet \mathrm{K}^{4}\right) ; T_{\text {sky }}$ is the sky temperature, the unit is $K$; $h_{c}$ is the convective heat transfer coefficient, take $12 \mathrm{~W} /\left(\mathrm{m}^{2} \bullet \mathrm{K}\right) ; T_{a}$ is the outdoor air temperature, the unit is $\mathrm{K} ; T_{r}$ is the indoor air temperature, the unit is $\mathrm{K} ; R_{0}$ is the thermal resistance of the enclosure structure, the unit is $\mathrm{m}^{2} \bullet \mathrm{K} / \mathrm{W} ; R_{i}$ is the thermal resistance of the inner surface of the green building materials, taking $0.11 \mathrm{~m}^{2} \bullet \mathrm{K} / \mathrm{W} ; x_{s k y}$ is the angular coefficient of the outer surface of the green 
building materials relative to the sky; $x_{g}$ is the angular coefficient of the outer surface of the green building materials relative to the ground (i.e., the area below the horizontal line); $\varepsilon_{g}$ is the hemispheric radiance of the ground.

The calculation of the external surface temperature amplitude and the limit temperature difference of green building materials are based on Equations (3) and (4):

$$
\begin{aligned}
& \Delta T_{s}=T_{s . \max }-\bar{T}_{s} \\
& \Delta T_{s . \max }=T_{s . \max }-T_{s . \min }
\end{aligned}
$$

where, $\Delta T_{s}$ is the temperature volatility of the outer surface of the green building materials in summer, the unit is $\mathrm{K} ; \bar{T}_{s}$ is the average temperature of the outer surface of the green building materials in summer, the unit is $\mathrm{K} ; T_{\text {s.max }}$ is the highest temperature of the outer surface of the green building materials in summer, the unit is $\mathrm{K} ; \Delta T_{\text {s.max }}$ is the maximum temperature difference between the day and night of the outer surface of the green building materials, the unit is $\mathrm{K} ; T_{\text {s.min }}$ is the minimum night temperature of the outer surface of the green building materials in summer, the unit is $\mathrm{K}$.

\subsubsection{Equivalent thermal resistance index of green building materials}

In the existing green building design standards, the prescriptive indicators for the thermal performance of walls and roofs are dominated by the control of heat transfer coefficients (Amin et al., 2016). Therefore, the contribution of the green building materials insulation effect to the energy saving of the ecological environment would be very convenient if calculated by the equivalent heat group (or equivalent heat resistance). The calculation of the equivalent thermal resistance is mainly based on the comprehensive temperature method theory in load calculation (Zhang et al., 2018). First, the correction factor for the heat transfer coefficient in summer and winter is calculated. Then, the annual comprehensive correction coefficient is calculated to obtain the equivalent thermal resistance, as follows.

(1) Correction value of heat transfer coefficient in summer

Compared with ordinary building materials, the correction coefficient $v_{s}$ of the wall heat transfer coefficient of green building materials throughout the summer can be calculated by the following formula:

$$
\begin{aligned}
v_{s} & =T_{a}+\frac{(1-\rho) I}{\alpha_{e}}-\frac{\alpha_{e r}\left(T_{a}-T_{s}\right)}{\alpha_{e}}-T_{r} \\
\alpha_{e r} & =\varepsilon C_{b} \theta \\
W & =K F_{W} \sum_{i}^{s} F_{i} \\
& =K F_{W} \sum_{i}^{s}\left(T_{a}+\frac{(1-\rho) I}{\alpha_{e}}-\frac{\varepsilon C_{b} \theta\left(T_{a}-T_{s}\right)}{\alpha_{e}}-T_{r}\right)
\end{aligned}
$$

$$
v_{s}=\frac{K F_{w} \sum_{i}^{s}\left(T_{a}+\frac{\left(1-\rho_{r}\right) l}{\alpha_{e}}-\frac{\varepsilon_{r} C_{b} \theta\left(T_{a}-T_{s}\right)}{\alpha_{e}}-T_{r}\right)}{K F_{w} \sum_{i}^{s}\left(T_{a}+\frac{\left(1-\rho_{n}\right) I}{\alpha_{e}}-\frac{\varepsilon_{n} C_{b} \theta\left(T_{a}-T_{s}\right)}{\alpha_{e}}-T_{r}\right)}
$$

where $F_{i}$ is the temperature difference load of the enclosure structure; $\varepsilon r$ is the hemispherical emissivity of green building materials; $\varepsilon_{n}$ is the hemispherical emissivity of ordinary building materials; $K$ is the heat transfer coefficient of the building exterior wall, the unit is $\mathrm{W} /\left(\mathrm{m}^{2} \bullet \mathrm{K}\right) ; F_{W}$ is the outer wall area of the building, the unit is $\mathrm{m}^{2} ; \sum_{i}^{s}$ is the integral of the time, indicating the superposition of the temperature difference load during the calculation period (Zhou et al., 2017); $\rho_{r}$ is the absorption ratio of solar building materials to solar radiation; $\rho_{n}$ is the absorption ratio of ordinary building materials to solar radiation (Gu et al., 2019; Wang et al., 2019); $\theta$ is temperature at the inner surface.

The reflectance of green building materials is usually larger than that of ordinary building materials, and the absorption ratio is also smaller than that of ordinary building materials (Hroudová et al., 2017), so the correction factor of the heat transfer coefficient $v_{s}<1$ in summer.

(2) Correction value of heat transfer coefficient in winter

In winter, the temperature set by the indoor air conditioner is higher than the outdoor temperature, and the expression of correction coefficient $v_{w}$ is:

$$
v_{w}=\frac{K F_{w} \sum_{i}^{s}\left(T_{R}-T_{a}+\frac{\left(1-\rho_{r}\right) I}{\alpha_{e}}-\frac{\varepsilon_{r} C_{b} \theta\left(T_{a}-T_{s}\right)}{\alpha_{e}}\right)}{K F_{w} \sum_{i}^{s}\left(T_{R}-T_{a}+\frac{\left(1-\rho_{n}\right) I}{\alpha_{e}}-\frac{\varepsilon_{n} C_{b} \theta\left(T_{a}-T_{s}\right)}{\alpha_{e}}\right)}
$$

In winter, the correction factor of the heat transfer coefficient $v_{w}>1$.

(3) Correction value of heat transfer coefficient throughout the year

The comprehensive effect of green building materials on heat insulation in summer and insulation effect in winter of the building, the correction coefficient vo of the annual heat transfer coefficient is obtained as follows:

$$
v_{0}=\frac{v_{s} E_{c}+v_{w} E_{h}}{E_{c}+E_{h}}
$$

where $E_{\mathrm{c}}$ is the annual electricity consumption for heating, the unit is $\mathrm{kW} \bullet \mathrm{h} / \mathrm{m}^{2}$, which is determined according to HDD18 (the number of heating days) in different regions; $E_{\mathrm{h}}$ is the annual power consumption of air conditioners, the unit is $\mathrm{kW} \bullet \mathrm{h} / \mathrm{m}^{2}$, which is determined according to CDD26 (number of air conditioning days) in different regions.

\subsubsection{Maximum internal surface temperature and thermal inertia index of green building materials}

According to the description of the thermal insulation properties of building materials in the relevant GB50176 specification, the thermal insulation properties of building facades or roofing can be characterized by the highest temperature inside the summer surface (Mavrikakis et al., 
2017). The solar reflectance and hemispherical emissivity of the outer surface are important factors influencing the thermal insulation performance. The insulation effect can be evaluated by calculating the highest temperature of the inner surface $\left(\theta_{i \cdot \max }\right)$ of the green building materials for different climatic conditions and green building materials by the following formula.

$$
\begin{aligned}
& \theta_{i \cdot \max }=\bar{\theta}_{i}+\left(\frac{A_{t s a}}{v_{0}}+\frac{A_{t i}}{v_{i}}\right) \beta \\
& \bar{\theta}_{i}=\bar{T}_{i}+\frac{\overline{T_{s a}}-\overline{T_{i}}}{R_{0} \alpha_{i}} \\
& \overline{T_{s a}}=\overline{T_{e}}+\frac{\bar{I}(1-\rho)}{\alpha_{e}}-\frac{\varepsilon_{r} C_{b} \theta\left(\overline{T_{e}}-T_{s}\right)}{\alpha_{e}}
\end{aligned}
$$

where, $\theta_{\text {i.max }}$ is the highest temperature of the inner surface; $\bar{\theta}_{i}$ is the average temperature of the inner surface; $A_{\text {tsa }}$ is the amplitude of the outdoor integrated temperature; $A_{\mathrm{ti}}$ is the amplitude of the indoor temperature; $v_{0}$ is the attenuation factor of the enclosure structure; $v_{i}$ is the attenuation factor of indoor air to the inner surface; $\beta$ is the phase difference correction coefficient; $\bar{T}_{i}$ is the indoor average temperature, $\bar{T}_{i}=\bar{T}_{e}+1.5 ; \bar{T}_{s a}$ is the outdoor integrated average temperature; $\bar{T}_{e}$ is the outdoor average temperature; $R_{0}$. is the thermal resistance of the enclosure, $\mathrm{m}^{2} \bullet \mathrm{K} / \mathrm{W}$.

Calculating the maximum temperature of the inner surface is cumbersome. In practical engineering applications, the thermal inertia $D$ value is often used to simplify the thermal insulation properties of the envelope structure (Gao et al., 2016). Therefore, calculating the reflectance of different sunlight has a strong practicality for the correction coefficient $\delta d$ of the $D$ value.

$$
\begin{aligned}
& D=R \cdot S=R \cdot \sqrt{\frac{2 \pi \lambda g c}{T}}=R \cdot \sqrt{\frac{2 \pi d g c}{T \cdot R}} \\
& \delta_{d}=\frac{D_{r}}{D_{n}}=\frac{R_{r} \cdot \sqrt{\frac{2 \pi d g c}{T \cdot R_{r}}}}{R_{n} \cdot \sqrt{\frac{2 \pi d g c}{T \cdot R_{n}}}}=\left(\frac{R_{r}}{R_{n}}\right)^{1 / 2}=\left(\frac{\frac{1}{v_{s}}-0.15 K}{1-0.15 K}\right)^{1 / 2}
\end{aligned}
$$

where, $D$ is the thermal inertia index value of the envelope structure; $\delta_{d}$ is the thermal inertia index correction coefficient of the envelope structure; $R$ is the thermal resistance of the envelope; $S$ is the heat storage coefficient of the envelope structure; $\lambda$ is the average thermal conductivity of the envelope structure; $g$ is the density of the envelope structure, $\mathrm{kg} / \mathrm{m}^{3} ; c$ is the specific heat capacity of the envelope structure, $\mathrm{J} /(\mathrm{g} \bullet \mathrm{K}) ; D_{r}$ is the thermal inertia index of the envelope structure when using green building materials; $D_{n}$ is the thermal inertia index of the envelope structure when using ordinary building materials.

Based on the above analysis, using the measurement method similar to lioka and Akira to measure the thermal insulation performance of paper cups, the parameters (temperature factor) that reflect the overall insulation effect of green building materials in a certain temperature range are proposed under low temperature conditions. (Temperature below $400{ }^{\circ} \mathrm{C}$ )

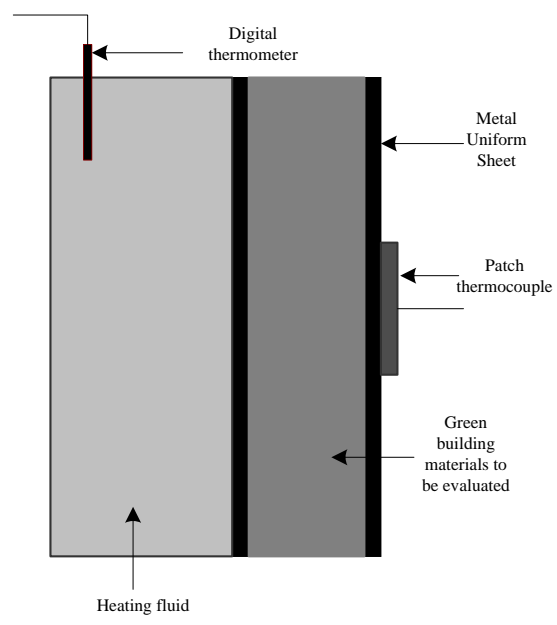

Figure 1. The schematic principle of testing the thermal insulation effect of green building materials

Table 1. Outdoor Temperature Changes On 27 July

\begin{tabular}{cccc}
\hline Time & $\begin{array}{c}\text { Temperature } \\
\left({ }^{\circ} \mathrm{C}\right)\end{array}$ & Time & Temperature $\left({ }^{\circ} \mathrm{C}\right)$ \\
\hline $1: 00$ & 25.06 & $13: 00$ & 40.81 \\
\hline $2: 00$ & 25.03 & $14: 00$ & 42.77 \\
\hline $3: 00$ & 25.46 & $15: 00$ & 39.38 \\
\hline $4: 00$ & 26.02 & $16: 00$ & 36.25 \\
\hline $5: 00$ & 26.85 & $17: 00$ & 33.16 \\
\hline $6: 00$ & 27.54 & $18: 00$ & 30.70 \\
\hline $7: 00$ & 28.09 & $19: 00$ & 28.36 \\
\hline $8: 00$ & 29.33 & $20: 00$ & 27.44 \\
\hline $9: 00$ & 32.46 & $21: 00$ & 26.86 \\
\hline $10: 00$ & 35.41 & $22: 00$ & 26.62 \\
\hline $11: 00$ & 38.10 & $23: 00$ & 25.17 \\
\hline $12: 00$ & 39.66 & $0: 00$ & 25.02 \\
\hline
\end{tabular}

2.2. Insulation effect evaluation principle and mathematical model of green building materials

Figure 1 is a schematic diagram of the evaluation principle of the green building materials insulation effect. The test is carried out under standard conditions of ambient temperature and humidity $\left(23^{\circ} \mathrm{C} \pm 1{ }^{\circ} \mathrm{C}, 50 \% \pm 2 \%\right)$. The green building materials sample to be evaluated is placed between two metal heat sinks (Arora et al., 2016), and the hot surface (outer surface) is heated by a digital temperature-controlled water bath (high temperature materials can be heated by hot oil) with an accuracy of \pm $0.2{ }^{\circ} \mathrm{C}$; the cold surface (inner surface) is mounted on a metal heat spreader with a patch-type thermocouple ( $\mathrm{Ya}$, 2017) with an accuracy of $\pm 0.2^{\circ} \mathrm{C}$. The temperature of the water bath was adjusted by a digital thermostat, and the temperature values of the cold and hot surfaces of the green building materials in the measurement interval were dynamically recorded.

The temperature deviation curve of the green building materials is made based on the obtained measurement results. The farther away from the standard line is, the better the insulation effect of green building materials is 
(Lu et al., 2016; Wang et al., 2018). This curve can only be qualitatively evaluated, especially when multiple sample curves are closely aligned or partially intersected, which cannot be accurately distinguished and judged (Feng et al., 2018). Therefore, quantitative characterization is needed

Table 2. Fitting Curve Equations of Temperature Deviation Curves on the outer Surface of Samples on July 27

\begin{tabular}{cccc}
\hline Sample number & Linear regression equation & Correlation coefficient & $\boldsymbol{\omega}$ \\
\hline Sample 1 & $\mathrm{y}=16.14278+0.55233 \mathrm{x}$ & 0.9924 & 278.27 \\
\hline Sample 2 & $\mathrm{y}=7.23556+0.72133 \mathrm{x}$ & 0.9896 & 215.42 \\
\hline Sample 3 & $\mathrm{Y}=4.43+0.88467 \mathrm{x}$ & 0.9997 & 67.62 \\
\hline
\end{tabular}

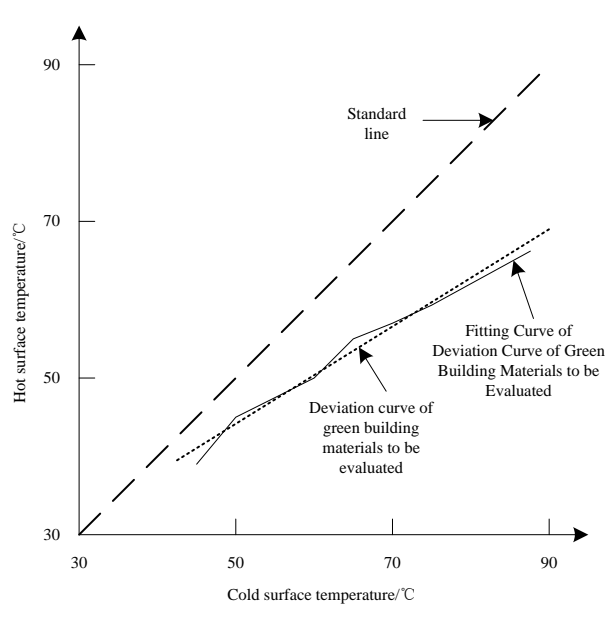

Figure 2. The change of cold surface temperature with hot surface temperature of green building materials

According to Figure 2, the equation for the fitting curve is obtained:

$$
t_{c}=f\left(t_{h}\right)
$$

where, $t_{c}$ indicates the cold surface temperature of the green building materials; $t_{h}$ indicates the hot surface temperature of the green building materials.

Assume that the temperature range under the application condition of green building materials is $\left(t_{1}, t_{2}\right)$, and the integral area between the fitted curve and the standard line is obtained in the interval, and the value of the integrated area is used as the insulation effect evaluation parameters of the green building materials in the interval (Xiao et al., 2017). It is a temperature factor, expressed as $\omega$, and the expression is as follows:

Temperature factor $\omega$ characterizes the average insulation effect of different indicators such as external surface temperature, equivalent thermal resistance, maximum internal surface temperature, and thermal inertness over a range of temperatures (Li et al., 2016). The larger the $\omega$ is, the larger the average temperature difference is. The better the insulation effect is, the lower the energy consumption is (Liu et al., 2018). The unit of temperature factor is ${ }^{\circ} \mathrm{C}^{2}$.

\section{Results}

This paper constructs an insulation effect evaluation model of green building materials for evaluating the insulation effect of the external maintenance structure. A famous green building in a certain city of China is taken as the to scientifically evaluate the insulation effect of green building materials. To this end, the fitting curve of the cold and hot surface temperature deviation curve of the green building materials is further obtained, as shown in Figure 2. research object, and relevant analysis is carried out. The result is as follows.

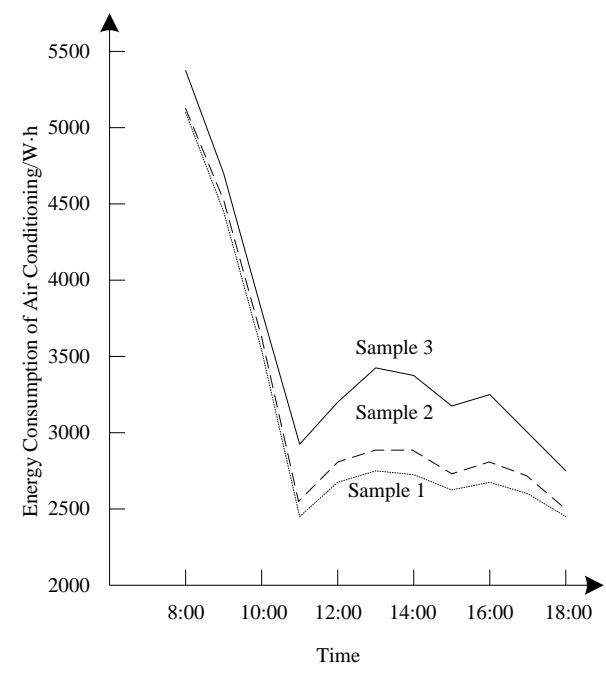

Figure 3. Energy consumption change of air conditioning on July 27

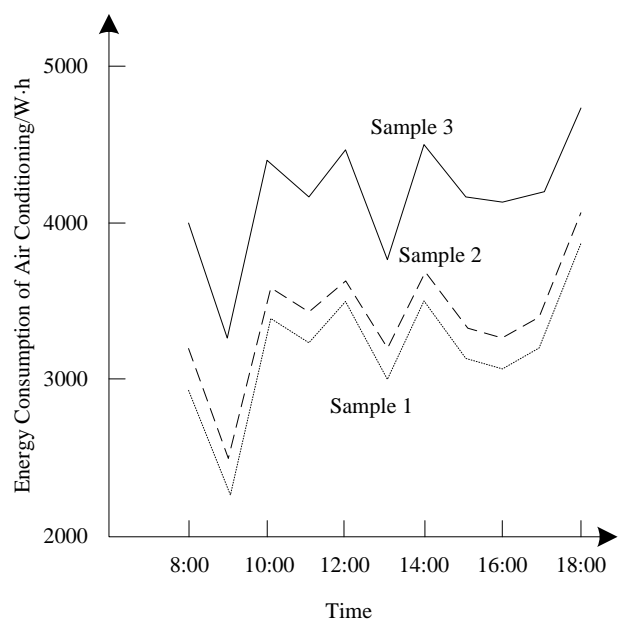

Figure 4. Variation of air-conditioning energy consumption on December 31

\subsection{Analysis of the evaluation results}

Find the hottest day and the coldest day of the year in which the study is located, using their meteorological data as a disturbance factor. Two green building materials and one common building material were labeled as Sample 1, Sample 2 and Sample 3, respectively (Xiao et al., 2018). When the temperature factor $\omega$ is used as the characterization of the overall thermal insulation 
performance in the temperature range of $-20^{\circ} \mathrm{C}-50^{\circ} \mathrm{C}$, the model is used to evaluate the thermal insulation effect of different building materials in this interval, and compare the amount of air conditioning energy consumption for different building materials at the same time point. The result is as follows.

Analysis Tables 1 and 2 show that July 27 is the hottest day in the city where the research object is located. In this environment, the temperature factors of green building materials are 287.27 and 215.42 , respectively, while the temperature factor of ordinary building materials samples is 67.62. The temperature factor of green building materials is significantly higher than that of common building materials, indicating that green building materials have a good insulation effect. Figure 3 shows that the overall trend of analysis of the three building materials is consistent, but there is a significant difference in air conditioning energy consumption. Sample 3 (ordinary building materials) consumes the most energy, and the energy consumption of a single-day air conditioner reaches $39,015 \mathrm{~W} \cdot \mathrm{h}$, which is determined by its cross-insulation effect. The other two green building materials have a small energy consumption difference (Singh et al., 2018). Compared with sample 3 , the energy consumption of single-day air conditioners was saved by about $14 \%$, and the results were consistent with the evaluation results of building material temperature factors.

Table 3. Outdoor Temperature Changes On 31 December

\begin{tabular}{cccc}
\hline Time & Temperature $\left({ }^{\circ} \mathrm{C}\right)$ & Time & $\begin{array}{c}\text { Temperature } \\
\left({ }^{\circ} \mathrm{C}\right)\end{array}$ \\
\hline $1: 00$ & -16.08 & $13: 00$ & 5.04 \\
\hline $2: 00$ & -16.00 & $14: 00$ & 6.98 \\
\hline $3: 00$ & -15.75 & $15: 00$ & 4.34 \\
\hline $4: 00$ & -11.24 & $16: 00$ & 1.73 \\
\hline $5: 00$ & -10.33 & $17: 00$ & -3.15 \\
\hline $6: 00$ & -8.82 & $18: 00$ & -8.17 \\
\hline $7: 00$ & -8.13 & $19: 00$ & -12.33 \\
\hline $8: 00$ & -7.50 & $20: 00$ & -14.06 \\
\hline $9: 00$ & -2.86 & $21: 00$ & -15.31 \\
\hline $10: 00$ & 1.36 & $22: 00$ & -15.60 \\
\hline $11: 00$ & 4.11 & $23: 00$ & -16.22 \\
\hline $12: 00$ & 5.00 & $0: 00$ & -16.41 \\
\hline
\end{tabular}

From Tables 3 and 4, and Figure 4, December 31 is the coldest day in the city where the study is conducted. Due to the difference in solar radiation variation law, the change of winter temperature factor and the change of air conditioning energy consumption are significantly different from those in summer. However, the conclusions of the temperature factor evaluation and energy consumption of the three building materials are consistent with the summer (Kang et al., 2018). Since the outdoor temperature in winter is much lower than the comfortable temperature setting of $18^{\circ} \mathrm{C}$, the energy consumption of air conditioning in one day is much higher than that in summer, so the energy consumption during heating in winter is high. The experimental results show that the model can accurately reflect the overall insulation effect of green building materials under the combined influence of various indicators in a certain temperature range.

\subsection{Comparison of roof and indoor temperature}

The model in this paper was used to evaluate the temperature inside the roof, the outer surface temperature and the indoor temperature under different climatic conditions. The results are shown in Tables 5 and 6 .

Since the roof is directly affected by solar radiation, its surface temperature varies greatly with time, and the highest temperature in summer can reach nearly $60^{\circ} \mathrm{C}$. The surface temperature inside the shed is obviously lower than the outer surface temperature. Especially at noon outside the shed, the temperature difference between the inner and outer surfaces of the shed can reach $19{ }^{\circ} \mathrm{C}$ (Chen et al., 2018). In the morning and noon, the external temperature is higher than the inner surface, and in the evening, the inner surface temperature is higher than the outer surface temperature. This law indicates that the green material used in the building has the characteristics of slow heating and slow cooling, reflecting its thermal insulation performance (Golui et al., 2018). It can be seen from Table 6 that the temperature of the outer surface of the building shed in winter fluctuates greatly, and the daily temperature difference can reach $20^{\circ} \mathrm{C}$. The fluctuation of the inner surface temperature of the shed is small, which indicates that the insulation effect of the green building materials plays a role in preventing cold.

\subsection{Evaluation and actual value of the highest temperature index on the inner surface}

The model was used to evaluate the highest temperature value of the inner surface of the study object, and the evaluation results were compared with the actual values. The results obtained are shown in Table 7.

According to the analysis Table 7, the fitting of the highest temperature evaluation value of the inner surface of the outer protective structure to the actual value is good. The difference between the temperature evaluation value and the actual value of the research object wall and the inner surface of the roof is basically controlled within $0.1{ }^{\circ} \mathrm{C}$, the lowest is $0.03{ }^{\circ} \mathrm{C}$, and the average difference is about 0.07 ${ }^{\circ} \mathrm{C}$. The analysis results show that the model has higher precision in evaluating the insulation effect of the green building materials.

\section{Discussion}

This paper constructs an insulation effect evaluation model of green building materials for evaluating the insulation effect of the external maintenance structure. A famous green building in a certain city of China is taken as the research object, and relevant analysis is carried out.

This paper uses the model to evaluate the insulation effect under different building materials conditions and analyze the energy consumption of air conditioning. In summer, the sample temperature factors for green building materials are 287.27 and 215.42 , respectively, which is significantly higher than the temperature factor of common building material samples. It shows that green building materials have a good insulation effect, and the comparison of air conditioning energy consumption also verifies the evaluation results. Due to the different solar radiation intensity of outdoor thermometers, the temperature factor 
evaluation results of green building materials in winter are different from those in summer, but the overall trend is consistent.

Table 4. Fitting Curve Equation of Temperature Deviation Curve of Outer Surface of Samples on Dec. 31

\begin{tabular}{cccc}
\hline Sample number & Linear regression equation & Correlation coefficient & $\omega$ \\
\hline Sample 1 & $y=15.25389+0.46344 x$ & 0.9936 & 245.38 \\
\hline Sample 2 & $y=7.14667+0.63244 x$ & 0.9907 & 194.24 \\
\hline Sample 3 & $Y=4.34251+0.79578 x$ & 0.9986 & 55.44 \\
\hline
\end{tabular}

Table 5. Summer Roof and Indoor Temperature of Building Structures

\begin{tabular}{ccccc}
\hline \multicolumn{2}{c}{ Time } & $\begin{array}{c}\text { Inner surface temperature of roof } \\
\left({ }^{\circ} \mathbf{C}\right)\end{array}$ & Surface temperature of roof $\left({ }^{\circ} \mathbf{C}\right)$ & Indoor temperature $\left({ }^{\circ} \mathbf{C}\right)$ \\
\hline \multirow{2}{*}{26} & $8: 00$ & 28.06 & 31.62 & 34.22 \\
\cline { 2 - 5 } July & $14: 00$ & 34.36 & 40.61 & 26.85 \\
\cline { 2 - 5 } & $19: 00$ & 30.61 & 27.14 & 26.83 \\
\hline \multirow{2}{*}{27} & $8: 00$ & 27.33 & 28.96 & 29.79 \\
\cline { 2 - 5 } July & $14: 00$ & 33.62 & 42.34 & 22.99 \\
\cline { 2 - 5 } & $19: 00$ & 27.20 & 23.81 & 23.78 \\
\hline \multirow{2}{*}{28} & $8: 00$ & 26.09 & 29.50 & 29.50 \\
\cline { 2 - 5 } July & $14: 00$ & 34.11 & 53.29 & 26.33 \\
\hline \multirow{2}{*}{29} & $19: 00$ & 29.38 & 28.12 & 24.71 \\
\cline { 2 - 5 } & $14: 00$ & 27.04 & 31.61 & 29.02 \\
\hline
\end{tabular}

Table 6. Winter Roof and Indoor Temperature of Building Structures

\begin{tabular}{|c|c|c|c|c|}
\hline \multicolumn{2}{|c|}{ Time } & $\begin{array}{l}\text { Inner surface temperature of roof } \\
\left({ }^{\circ} \mathrm{C}\right)\end{array}$ & $\begin{array}{l}\text { Surface temperature of roof } \\
\left({ }^{\circ} \mathrm{C}\right)\end{array}$ & Indoor temperature $\left({ }^{\circ} \mathrm{C}\right)$ \\
\hline \multirow{3}{*}{$\begin{array}{l}\text { December } \\
\quad 31\end{array}$} & $8: 00$ & 3.82 & -7.48 & -1.31 \\
\hline & $14: 00$ & 5.94 & 6.96 & 3.43 \\
\hline & 19:00 & 1.38 & -12.31 & -1.32 \\
\hline \multirow{3}{*}{ January 1} & $8: 00$ & -1.01 & -8.62 & -0.19 \\
\hline & $14: 00$ & 10.63 & 10.42 & 9.69 \\
\hline & 19:00 & 7.49 & -2.49 & 6.80 \\
\hline \multirow{3}{*}{ January 2} & $8: 00$ & -0.82 & -7.11 & 0.61 \\
\hline & $14: 00$ & 13.88 & 14.90 & 8.03 \\
\hline & 19:00 & 5.90 & -5.48 & 3.58 \\
\hline \multirow{3}{*}{ January 3} & $8: 00$ & -0.91 & -7.19 & 0.49 \\
\hline & $14: 00$ & 12.72 & 14.76 & 7.87 \\
\hline & 19:00 & 5.77 & -5.63 & 3.50 \\
\hline
\end{tabular}

Table 7. Comparisons of The Maximum Temperature of The Inner Surface of The Periphery Envelope with the Actual Values

\begin{tabular}{|c|c|c|c|c|}
\hline & Peripheral enclosure structure & Value of assessment & Actual value & Difference value \\
\hline \multirow{4}{*}{ Wall } & Maximum Temperature of Inner Surface of Eastern Wall $\left({ }^{\circ} \mathrm{C}\right)$ & 39.29 & 39.18 & 0.11 \\
\hline & Maximum Temperature on the Inner Surface of South Wall $\left({ }^{\circ} \mathrm{C}\right)$ & 39.66 & 39.71 & 0.05 \\
\hline & Maximum Temperature on the Inner Surface of West Wall $\left({ }^{\circ} \mathrm{C}\right)$ & 38.58 & 38.61 & 0.03 \\
\hline & Maximum Temperature on the Inner Surface of North Wall $\left({ }^{\circ} \mathrm{C}\right)$ & 38.28 & 38.19 & 0.09 \\
\hline \multirow{4}{*}{ Ceiling } & Maximum Inner Surface Temperature at Northwest Point $\left({ }^{\circ} \mathrm{C}\right)$ & 42.47 & 42.54 & 0.07 \\
\hline & Maximum Inner Surface Temperature at Southwest Point $\left({ }^{\circ} \mathrm{C}\right)$ & 42.21 & 42.15 & 0.06 \\
\hline & Maximum Inner Surface Temperature at Northeast Point $\left({ }^{\circ} \mathrm{C}\right)$ & 42.39 & 42.46 & 0.07 \\
\hline & Maximum Temperature of Inner Surface at Southeast Point $\left({ }^{\circ} \mathrm{C}\right)$ & 42.29 & 42.39 & 0.10 \\
\hline
\end{tabular}

The insulation effect is an important parameter for green building design. In the hot summer, the solar radiation affects the indoor warm environment through the building maintenance structure, which hinders the radiation dissipation of indoor people and aggravates the heat stress of the human body. The roof is the enclosure that receives the most solar radiation during the hot season. In particular, attention should be paid to the insulation effect of roofing building materials. In this experiment, since the roof is directly affected by solar radiation, its surface temperature varies greatly with time, and the highest temperature in summer can reach nearly $60^{\circ} \mathrm{C}$. The surface temperature inside the shed is obviously lower than the outer surface temperature. Especially at noon outside the shed, the temperature difference between the inner and outer surfaces of the shed can reach $19^{\circ} \mathrm{C}$, which indicates 
that the green building materials used in the roof effectively reduce the heat transfer effect.

From the perspective of the evaluation model, the average difference between the evaluation value and the actual value is about $0.07{ }^{\circ} \mathrm{C}$, which indicates that the evaluation model of this paper has high credibility. The evaluation model in this paper is feasible in evaluating the thermal insulation properties of green building materials. When the roof is made of materials with high thermal resistance and thermal inertia, the insulation effect is more significant. According to the analysis of thermal parameters, it is found that the total thermal resistance of the building's outer protective structure affects the average temperature of the inner surface, while the thermal inertia index has a significant impact on the total attenuation and total delay time. Therefore, the insulation effect of the roof has a great effect on the control of the indoor temperature.

\section{Conclusions}

At present, the standards for thermal insulation of green building materials in China are mainly for reflective green building materials, and there are few standards related to some other types of green building materials such as radiation type. Although different standards have slightly different evaluation methods and limits for related indicators, the solar reflectance and hemispheric reflectance are basically used as the main evaluation indicators and technical parameters of green building materials. This paper constructs the insulation effect evaluation model of green building materials under ecological environment. The external surface temperature index, the equivalent thermal resistance index, the thermal inertia and the highest temperature index on the inner surface are used to evaluate the insulation effect of the green building materials. This study provides the necessary basic data to further optimize the thermal insulation structure of green buildings and analyze energy conservation and consumption reduction.

\section{References}

Abdikadir A.O., Md. Sahadat H. and Mst. M.P. (2018), Study on knowledge, attitude and practices towards the solid waste management in Karan District, Mogadishu Somalia. Environmental Contaminants Reviews, 1(2), 22-26.

Achille D.F. and Enow A.D. (2020), Evaluating the bidirectional nexus between climate change and agriculture from a global perspective. Malaysian Journal of Sustainable Agriculture, 4(1), 40-43.

Amin A., Ahmed E.H. and Sabaa M.W. (2016), Preparation and evaluation of hyperbranched P-chloromethyl Styrene polymers/montmorillonite clay nanocomposites as dielectric materials. Polymer Bulletin, 73(1), 147-162.

Arora V., Mulaveesala R. and Bison P. (2016), Effect of spectral reshaping on frequency modulated thermal wave imaging for non-destructive testing and evaluation of steel material. Journal of Nondestructive Evaluation, 35(1), 1-7.

Cappello T., Santarelli A. and Florian C. (2017), Dynamic RON characterization technique for the evaluation of thermal and off-state voltage stress of GaN switches, IEEE Transactions on Power Electronics, (99), 1-1.
Ch. A., Asma S., Do M.C., Faizan U.H.K., Abdul N., Zia B. and Fariha I. (2018), Study of spatial and temporal variability of arsenic in groundwater due to drain by using gis, Earth Sciences Pakistan, 2(2), 22-24.

Chen S. and Hassanzadeh-Aghdam M.K., et al. (2018), An Analytical model for elastic modulus calculation of sic whisker-reinforced hybrid metal matrix nanocomposite containing sic nanoparticles. Journal of Alloys and Compounds, 767, 632-641.

D’Agata C., Diolaiuti G., Maragno D., Smiraglia C. and Pelfini M. (2020), Climate change effects on landscape and environmen $\mathrm{t}$ in glacierized Alpine areas: retreating glaciers and enlarging forelands in the Bernina group (Italy) in the period 19542007, Geology, Ecology, and Landscapes, 4:1, 71-86.

Feng X.L., Li B.J. and Yuan Y.Q. (2018), Environmental sensitivity stress evaluation of bipolar silver-zinc reserve battery. Chinese Journal of Power Sources, 42(11), 128-130.

Gao J., Yang L. and Wang Y. (2016), Effect of moisture and thermal degradation on the activation energy of oil-paper insulation in frequency domain spectroscopy measurement, let Generation Transmission \& Distribution, 10(9), 2042-2049.

Geisler M. and Ebert H.P. (2016), Thermal characterization and effect of deposited $\mathrm{CO}_{2}$ on a cryogenic insulation system based on a spherical powder, International Journal of Thermophysics, 37(8), 1-18.

Golui D., Datta S.P. and Kaushik S.C. (2018), Interferences of medium and matrix in determination of trace toxic elements using inductively coupled plasma mass spectrometry, Journal of Environmental Biology, 39(1), 103-108.

Gu F., Zhang W., Guo J. and Hall P. (2019), Exploring "Internet plus Recycling": Mass balance and life cycle assessment of a waste management system associated with a mobile application, Science of the Total Environment, 649: 172-185.

Haţiegan C., Padureanu I. and Jurcu M.R. (2016), The evaluation of the insulation performances of the stator coil for the high power vertical synchronous hydro-generators by monitoring the level of partial discharges. Electrical Engineering, 99(3), 1-8.

Hroudová J., Sedlmajer M. and Pařilková J. (2017), Laboratory testing of developed thermal insulation plasters on pillars built from masonry bricks, Procedia Engineering, 172(Complete), 377-384.

Ibrahim S., Magaji J.I. and Isa Z. (2020), Simulation of sediment yield and supply on water flow in different subbasins of terengganu watershed from 1973-2017, Water Conservation and Management, 4(1), 01-06.

Kang L. and Du H.L., et al. (2018), Study on dye wastewater treatment of tunable conductivity solid-waste-based composite cementitious material catalyst, Desalination and Water Treatment, 125, 296-301.

Katsumata K., Tao W. and Ishiyama A. (2017), Influence of the turn-to-turn contact electrical resistance on the thermal stability in meter-class no-insulation REBCO pancake coils during a local normal-state transition, IEEE Transactions on Applied Superconductivity, 27(4), 1-5.

Li X.B., Bohanec M., Zhao L.T. (2016), Designing and developing DEXi evaluation models based on D2 framework, Automation \& Instrumentation, (4), 215-217.

Liu J., Liu Y. and Wang X. (2019), An environmental assessment model of construction and demolition waste based on system 
dynamics: a case study in Guangzhou, Environmental Science and Pollution Research International.

Liu Y., Zhang L.J. and Han Y.A. (2018), Financial credit risk evaluation model of supply chain finance based on particle swarm cooperative optimization algorithm, Journal of Jilin University (Science Edition), 56(1), 119-125.

Lu X.T. and Tan P.A. (2016), Modeling and analysis of electrothermal coupling model for SiC MOSFET, Journal of Power Supply, 14(6), 29-34.

Marangoni M., Nait-Ali B. and Smith D.S. (2017), White sintered glass-ceramic tiles with improved thermal insulation properties for building applications. Journal of the European Ceramic Society, 37(3), 1117-1125.

Mavrikakis N.C., Mikropoulos P.N. and Siderakis K. (2017), Evaluation of field-ageing effects on insulating materials of composite suspension insulators, IEEE Transactions on Dielectrics \& Electrical Insulation, 24(1), 490-498.

Mohammad K.U.S., Ahmad K.M., Md. Zahurul H., Md. Sahadat H. and Abdullah A.N. (2019), Assessment of inland water quality parameters of Dhaka City, Bangladesh, Environment \& Ecosystem Science, 3(1), 13-16.

Muto S., Fujita S. and Akashi K. (2018), Evaluation of actual delamination strength of REBCO coated conductors based on the weibull analysis considering size effect, IEEE Transactions on Applied Superconductivity, (99), 1-1.

Naeini A., Cherney E.A. and Jayaram S.H. (2019), Effect of conductivity on the thermal and electrical properties of the stress grading system of an inverter-fed rotating machine, IEEE Transactions on Dielectrics and Electrical Insulation, 26(1), 179-186.

Nwankwoala H.O. (2019), Geoethics as an emerging discipline: perspectives, ethical challenges and prospects, Earth Sciences Malaysia, 3(1), 1-8.

Povarov V.P. (2016), Evaluation of the effect of thermal stratification on the residual life of the surge line of the pressure compensator in the No. 5 Unit of the Novovoronezh NPP, Atomic Energy, 120(1), 22-28.

Puza C., Wang Q. and Kim C. (2018), 3:40 PM Abstract No. 346 evaluation of the heat sink effect in combination therapy with embolization and thermal ablation, Journal of Vascular and Interventional Radiology, 29(4), S148-S149.

Siti N.M.A., Muhammad F.K., Nik N.N.A. and Mohd F.M. (2019), Distribution pattern of rare earth elements in soft tissue of Saccostrea Cucullata in terengganu and east Johor Coastal waters, Journal Clean WAS, 3(2), 14-19.

Sumislawska M., Gyftakis K.N. and Kavanagh D.F. (2016), The impact of thermal degradation on properties of electrical machine winding insulation material, IEEE Transactions on Industry Applications, 52(4), 2951-2960.

Sun H., Zhang S. and Gao Y. (2019), Self-heating effect on stability of a nanosecond pulsed dbd interacting with heptane and methylnaphthalene as heavy oil model compounds, IEEE Transactions on Dielectrics and Electrical Insulation, 26(2), 431-438.

Wang H. and Zhong H., et al (2018), Existing forms and changes of nitrogen inside of horizontal subsurface constructed wetlands. Environmental Science and Pollution Research, 25(1), 771-781.

Wang M., Zhang D., Cheng Y. and Tan S.K. (2019), Assessing performance of porous pavements and bioretention cells for stormwater management in response to probable climatic changes. Journal of Environmental Management, 243, 157-167.

Xiao Q., Li D., Guo R., Zheng L., An X. and Zeng Z. (2018), In vivo and in vitro toxicities of diethyl phthalate to flounder fish paralichthys olivaceus and its gill cell line (FG cells), Journal of Environmental Biology, 39(1), 73-81.

Xiao S.A., Wu H. and Wang J.P. (2017), Research on effectiveness evaluation of integrated electronic information system based on multi-level modeling, Journal of China Academy of Electronics and Information Technology, (3), 257-261.

Ya L. (2017), Simulation model of rationality evaluation of construction cost of tall buildings. Computer Simulation, 34(9), 416-419.

Zhang J.W., Gao F.K. and Cao D.K. (2018), Modeling of charge transport in insulating dielectric for gas-insulated transmission line based on multiple trap levels, IEEE Transactions on Dielectrics and Electrical Insulation, 25(4), 1195-1201.

Zhou Y. and Wang S. (2017), Application effect of composite phase change energy storage thermal insulation mortar in solar greenhouse, Transactions of the Chinese Society of Agricultural Engineering, 33(20), 190-196.

Zoeller C., Vogelsberger M.A. and Fasching R. (2017), Evaluation and current-response-based identification of insulation degradation for high utilized electrical machines in railway application, IEEE Transactions on Industry Applications, (99), $1-1$. 